\title{
A PROPÓSITO DE LA REMOCIÓN DE LOS NAUFRAGIOS: DEL DERECHO ROMANO AL CONVENIO DE NAIROBI DE 2007
}

\author{
Tewise Ortega González ${ }^{1}$ \\ Yeray del Pino Álamo González ${ }^{2}$
}

\section{Resumen}

En el presente trabajo, pretendemos abordar algunos aspectos relativos al salvamento marítimo, centrándonos fundamentalmente en la remoción y extracción de restos procedentes de un incidente en la navegación, tratando de establecer un punto de conexión entre principios de base romanística sobre la materia objeto de estudio y lo dispuesto en el Convenio Internacional de Nairobi sobre la remoción de restos de naufragio, de 18 de mayo de 2007, y que entró en vigor el 14 de abril de $2015^{3}$ para los países firmantes del mismo. Para ello, nuestra metodología se basa en el análisis exegético de las fuentes romanas propuestas. Los resultados que se reflejan en las notas conclusivas permiten observar como existe conexión entre las normas de Derecho Romano y las normas contenidas en el Convenio.

Palabras clave: Convenio de Nairobi, Naufragium, Daño, Remoción, Responsabilidad.

\section{CONSIDERACIONES PREVIAS SOBRE LA REMOCIÓN DE RESTOS AL AMPARO DEL CONVENIO DE NAIROBI}

Como consideración previa, y a modo de status quaestionis, hay que señalar que, hasta la firma de la Convención de Nairobi sobre Remoción de Restos Náufragos (en adelante CNRRN), no regían unos principios generales internacionales relativos a la tutela de la propiedad de los bienes naufragados o al abandono de bienes en aguas soberanas de los Estados. El 23 de mayo de 2007 la Organización Marítima Internacional (OMI) marcó las pautas para estructurar, elaborar y aprobar el texto de la Convención ${ }^{4}$, que pretendía entre otros aspectos, la consolidación de dos objetivos principales.

Por un lado, facilitar la remoción con la oportuna celeridad de los restos de cualquier naufragio,

\footnotetext{
${ }^{1}$ Doctora y profesora colaboradora del Área de Derecho romano del Departamento de Ciencias jurídicas Básicas de la Universidad de las Palmas de Gran Canaria. E-mail: tewise.ortega@ulpgc.es

${ }^{2}$ Profesor colaborador de del Área de Derecho romano del Departamento de Ciencias jurídicas Básicas de la Universidad de las Palmas de Gran Canaria. E-mail: yeray.alamo@ulpgc.es

${ }^{3}$ El Estado Español no ha ratificado el Convenio, por lo que en relación a esta materia, será de aplicación las disposiciones contenidas en la Ley 14/2014, de 24 de Julio, de la Navegación Marítima.

${ }^{4}$ DE LA RUE, Colin-ANDERSON, Charles B., Shipping and the environment, Londres, 2009, pp. 990 y 991.
} 
particularmente, aquellos que contengan bienes o mercancías consideradas peligrosas, garantizando la seguridad de la navegación y la protección del medio marino, adecuando la correcta y justa indemnización respecto de los costes que se hubieran ocasionado.

Por otro, establecer la obligatoriedad de la concertación de un seguro de responsabilidad para los buques de más de 300 Toneladas de Arqueo Bruto 5 .

El trabajo de la OMI duro casi 20 años, desde el año 1974 hasta el año 1993, cuando a instancia de países como Alemania, Grecia, Países Bajos y el Reino Unido, se reanudaron los trabajos para elaborar un compendio de normas de carácter internacional sobre la remoción de restos.

En otro orden de cosas, el Convenio introduce criterios precisos con el fin de evitar la continua contaminación marítima y atmosférica, relacionadas con las operaciones marítimas. En este contexto, por tanto, la Convención debía ser considerada como centro neurálgico del esfuerzo de la OMI para dirigir a la sociedad en la adopción de medidas para el cuidado del ya deteriorado y delicado ambiente marítimo.

En el texto del acuerdo, no solo se incluyen en la definición "restos" los buques varados o hundidos, sino cualquier parte de los mismos, los objetos del buque que hayan caído al mar, se encuentren varados, hundidos o a la deriva, sino también cualquier buque que está a punto de sumergirse o de quedar varado, o que se espera razonablemente que pueda hundirse, a pesar de haber intentado salvaguardar la integridad de la nave y de los bienes introducidos mediante la realización de operaciones de salvamento, donde se incluye a su vez, el concepto de siniestro proveniente de averías marítimas ${ }^{6}$, incidentes que acontecían en la antigua Roma y que fueron regulados de forma exhaustiva.

Es resaltable como quedan excluidos del ámbito de aplicación de este Convenio, los buques de guerra, así como los buques propiedad de los Estados que sean utilizados para fines no comerciales, siguiendo el principio de la inmunidad soberana ${ }^{7}$.

Al mismo tiempo, se reconoce que sólo se podrán adoptar y realizar labores de prevención por parte de los Estados no afectados por el incidente en la navegación, cuando el Estado perjudicado tenga conocimiento de la existencia de dichos restos en el área de la Convención, destacando que las disposiciones contenidas en éste, sólo serán de aplicación, si los restos representan un peligro para el Estado costero. En ese sentido, y partiendo de lo dispuesto en el texto del Convenio, entendemos por situaciones de peligro, aquellos accidentes en la navegación que se suceden próximos a rutas de navegación, zonas muy transitadas, o instalaciones portuarias

\footnotetext{
${ }^{5}$ Vid. Convenio Internacional Sobre Arqueo de Buques hecho en Londres, 23 de junio 1969

${ }^{6}$ ZAMORA MANZANO, José Luis, Averías y accidentes en derecho marítimo romano, Madrid, 2000, p.75-147 sobre algunos aspectos de estos incidentes.

${ }^{7}$ Véase CASELLA, Daniel Alejandro, "La inmunidad soberana y el embargo de un buque de guerra: el caso de A.R.A. Libertad", International Law, Revista Colombiana de Derecho Internacional, 23, julio a diciembre 2013, p. 17-52
} 
vulnerables.

Por otro lado, la CNRRN no identifica si estos requisitos son acumulativos, dejando al arbitrio de los Estados parte la incorporación de otros. Por todo ello, para garantizar la ejecución de la responsabilidad y respecto de la remoción, corresponde en primer lugar al propietario inscrito, el cual, también, es responsable de los costos de localización, balizamiento y remoción de los restos. El Estado afectado puede establecer las condiciones y el tiempo límite para que dichas actividades se lleven a cabo; si no se respeta ese tiempo, éste puede proceder a la remoción por sí mismo y recuperar mediante la interposición de acciones los costos de la operación.

De acuerdo con el tratado, y respecto del artículo $10,{ }^{8}$ los conceptos de la responsabilidad objetiva, pero limitada del propietario inscrito, y del derecho de los reclamantes de proceder directamente contra el asegurador o el proveedor de la garantía financiera "han sido desarrollados por la Organización para facilitar la pronta indemnización de los reclamantes sin necesidad de controversias jurídicas que podrían ser largas y costosas".

En este contexto, la Convención de Nairobi es un documento eminentemente práctico, que dota a los Estados ribereños de herramientas necesarias para llevar a cabo una tarea integral de limpieza en el ámbito geográfico determinado por la propia Convención.

Al hilo de lo argumentado, queremos destacar aspectos que guardan relación con el derecho romano, donde también encontramos principios que no dejan de ser los antecedentes de una institución moderna.

En Derecho Romano, no existió el concepto de remoción, tal y como aparece definido en la Convención, entendido como "toda forma de prevención, reducción o eliminación del riesgo generado por los restos de un naufragio", de modo que como antecedentes al mismo debemos remitirnos al llamado naufragium? que se caracterizaba por la recuperación de los efectos naufragados como consecuencia de accidentes en la navegación, y el respeto a la propiedad de los bienes sumergidos, no siendo posible, por las limitaciones técnicas de las naves, en el curso de una navegación ${ }^{10}$, el salvamento preventivo tendente a evitar el hundimiento de la embarcación, la pérdida de las mercancías o vidas humanas, mediante el auxilio o la asistencia en situaciones de peligro $^{11}$. Otro supuesto que podemos encuadrar en el concepto de remoción, desde una perspectiva romanística, es el auxilio que se prestaba a grandes embarcaciones para el acceso a los ríos o el atraque en los puertos, mediante

\footnotetext{
${ }^{8}$ HILL PRADOS, María Concepción, Los clubes de protección e indemnización en el campo del seguro marítimo, 1992.Barcelona.WEITZ, Leslie Tomasselo, "El seguro de Protección e indemnización y la acción directa contra el asegurador". Derecho Marítimo. 2012, Revista Javeriana, volumen 15, n 25, 2006.

${ }^{9}$ Como antecedente de la institución, existió lo que se conoce como ius naugragii, o derecho de las poblaciones de las costas, playas o riberas de los ríos, y de la propia annona, de apropiarse de las cosas provenientes de los naufragios, y que excluía las posibilidades de recuperación por el legítimo propietario, considerado extranjero, y como tal carente de protección jurídica. SCHIAPPOLI, D., Il ius naufragii secondo il diritto della Chiesa, RDN, v,4, 1938, pp 137-157.SCIALOJA V. v.naufragio, NDI, 7, 1939, p.865. MOSCHETTI,C.M. v. naufragio, ED. 547-558.

${ }^{10}$ MORRAL SOLDEVILLA, R., El salvamento marítimo. Especial referencia al Convenio de 1989. Barcelona, 1997, pp.57-83, GABALDON GARCÍA, J.L y RUIZ SOROA, J.M., Manual de derecho de la Navegación Marítima, Madrid 2006, pp. 712 y ss.
} 
el trasbordo de las mercancías a una nave de menor tamaño, la asistencia de barqueros y las operaciones de recuperación y extracción de mercancías hundidas por el cuerpo profesional de los urinatores.

\section{IUS NAUFRAGII. DERECHO A RECUPERAR LOS RESTOS Y SU REMOCIÓN}

El Derecho Romano conoció diversas normas encaminadas a tutelar los accidentes en la navegación, recogidas fundamentalmente en obras recopilatorias de las legislaciones imperiales, particularmente, en el Codex Theodosianus ${ }^{12}$ y en el Codex Iustinianus ${ }^{13}$, bajo el título de "De naufragiis".

En un principio, y antes de que se estableciera el principio de protección de la propiedad de los bienes naufragados, se reconocía la licitud de la recogida y extracción de las mercancías, al amparo de lo dispuesto en Ulpiano 8 de off. Proc,, contenido en D. 47.9.12 "Licere unicuique naufragium suum impune colligere constat: idque imperator Antoninus cum divo patre suo rescripsit", al igual que establece el CNRRN, que en la misma línea argumental, no sólo considera lícito, sino también obligatorio, la recogida de los restos procedentes de un naufragio.

Llegados a este punto, es importante rayar la superficie de lo que en tiempos de roma representó la figura de los urinatores. ${ }^{14}$. En la actualidad, podemos considerarlos como los equipos de submarinitas de élite o como las naves menores que dan sustento logístico y apoyo a las embarcaciones de mayor envergadura, con el fin de que pudieran acceder a determinados puntos de difícil acceso, y para ello realizaban labores de transbordo de mercancías de un barco a otro con el fin de nivelar las cargas, aunque en época romana, concretamente en el siglo IV a.C $\mathrm{C}^{15}$, donde nos consta esta relevancia histórica de su figura, se consideraban una primera unidad de buceadores militares con carácter permanente y profesional dedicada a las operaciones subacuáticas.

Sus misiones eran muy diversas, interesándonos por las labores de recuperación de anclas del fondo de las orillas de los mares y ríos, la instalación de defensas subacuáticas en los puertos y estuarios, la recuperación de mercancías de barcos hundidos, esta última de mayor relevancia para nuestro estudio. Aunque inicialmente fueron utilizados para la realización de acciones de carácter bélico, en tiempos de paz, y con la profesionalización del servicio de transporte y su conversión en una actividad de carácter eminentemente pública, los urinatores constituyeron un gremio, siendo los encargados de extraer los bienes que caían al agua durante los trabajos de carga y descarga en los puertos, pasando su función militar a un segundo plano.

\footnotetext{
${ }^{11}$ MORRAL SOLDEVILLA, R, op. cit. pp.57-83.GABALDON GARCÍA, J.L Y RUIZ SOROA, J.M., op.cit, pp. 712 y ss.

${ }^{12}$ C.Th.13.9, De naufragiis.

${ }^{13}$ C.11.6, De naufragiis.

14 ERNOUT-MEILLET, Dictionnaire etym. Langue latine, Paris 1959, 755. DIRKSEN, Manuale latinitatis fontium i.e.Romanorum, Berlín 1937, 1019 urinator(=qui sub aqua natat). HEUMANN SECKEL, Handlexikon z.d. Quellen des Romischen, 1914, 604 v. Urinator( Taucher).
} 
Ahora bien, volviendo a la línea argumental con este inciso que es merecedor de un estudio de mayor profundidad en líneas posteriores, debemos indagar sobre la situación jurídica en la que quedan los bienes arrojados al mar para aligerar la nave y evitar un accidente, o los hundidos como consecuencia de un incidente marítimo. Dichos extremos son fundamentales de cara a la determinación de la propiedad de los mismos y su consideración o no como res derelictiae.

El derecho de propiedad sobre los naves y otros bienes hundidos o arrojados con el objeto de salvaguardar la nave y sus pertrechos, superó la concepción primitiva del ius naufragiil' que permitía la apropiación de los bienes por aquellos que lo encontraran, adquiriendo una importancia fundamental en el estudio y la regulación del incidente de naufragio y el resto de accidentes marítimos, respetando y tutelando el derecho de propiedad ${ }^{17}$ frente a cualquier acto de latrocinio y despojo y cualesquiera derecho del fisco ${ }^{18}$, no aplicando el principio general de abandono que convierte al bien en una res nullius, y por tanto, susceptible de apropiación, considerando que tanto en la echazón de mercancías como en el hundimiento de la nave, no queda acreditada la intencionalidad del legítimo propietario de abandonar las mismas, "res autem iacta domini manet,

\footnotetext{
${ }^{15}$ Vease ZAMORA MANZANO, José Luis, "El Salvamento ...,pp.373 ss

${ }^{16}$ En una etapa más antigua, el apoderamiento de los bienes afectaba tanto a los bienes varados, que llegaban a la orilla por haber sido arrojados, a los naúfragos, como a las naves que atracaban en puerto sin autorización de las autoridades locales y que podían ser capturadas por los vecinos del lugar, que se apropiaban de las mercancías, y que, posteriormente provocaban los accidentes mediante la simulación de falsos faros. El Talmud de Jerusalém también reconoce la práctica del ius naufragii “los objetos salvados de las garras de un león ... de una tormenta en el mar... te pertenecen" añadiendo con posterioridad "en el caso que el propietario hubiera renunciado a ellas". Entendemos que esta apostilla es una influencia del concepto romano de derelictio, que admitió la pérdida del dominio sobre tales bienes siempre que exista intención de abandono por su legítimo propietario. Vid. PURPURA, G., Ius Naufragii, Sylai e Lex Rhodia ...,pp. 275 y ss. PURPURA, G., Relitti di navi e diritto del fisco. Una congettura sulla Lex Rhodia, AUPA 36, 1976 pp.280 y ss. PURPURA, G., La protezione dei giacimenti archeologici in acque internazionale e la Lex Rhodia del mare. In AA.VV. (a cura di), Mediterraneum. Tutela e valorizzazione dei beni culturali ed ambientali, Collana monografica per la tutela e valorizzazione dei beni culturali" dell'Università "L'Orientale" di Napoli, 2004, pp-13-27, 71-72, SCHIAPPOLI, D., Il ius naufragii secondo ..., p. 137-157. PINZONE, A., Naufragi, fisco e trasporti marittimi ..., p.68. ANDRICH, DI, v. Naufragio, t 2, Turín, 1904, p 1303-1312. ROUGÉ, J., Recherches sur ..., p.336.

${ }^{17} \mathrm{La}$ reiteración de la prohibición y el incremento de la pena no jugaron a favor del cumplimiento de la norma, Vid. Ulpiano 56, ad. Ed. en D.47.9.1 actio in cuadruplum, Paulo 54. ad. Ed. en D. 47.9.4, Paulo 34 ad. Ed., D.14.2.2.8, Gayo 2 en D.41.1.9.8 y Juliano 2 ex Min., D.14.2.8. Pasamos de la actio in quadruplum, a la rellegatio y la condena ad metalla en función de la calidad de las personas, de acuerdo a lo dispuesto por el Divino Antonino en D. 47.9.4.

${ }^{18}$ Por lo que respecta al posible derecho del fisco de retención y posterior venta de las mercancías arrojadas al mar para aligerar la nave en caso de tempestad, en aplicación de la Lex Rhodia, se reconoce la exención del pago del portorium por tales mercancías y la prohibición del decomiso en los casos de echazón para evitar el hundimiento. PINZONE, A., Naufragi, fisco e trasporti marittimi p.86. Volucio Meciano, ex lege Rhodia., D. 14.2.9, tutela el derecho de propiedad sobre los bienes naufragados al negar el derecho del fisco sobre las mercancías. Por su parte, Marciano, De Delat., D.39.4.16.8 excluye cualquier derecho del fisco "si propter necessitatem tempestatis expositum fuerit, rompiendo con la regla general aplicada por los publicanos, de exigir el pago del impuesto desde el momento en el que las mercancías tomen tierra. Al mismo tiempo, la constitución dada por el emperador Antonino a Máximo, recogida en la Constitución dada por el emperador Antonino a Máximo recogida en C. 11.6.1: "quando naufragio navis expulsa fueris ad littus, vel si quando reliquam terram attigerit, at dominos pertineat; fiscus meus sese non interponat. Quod enim ius habet fiscus meus in aliena calamitate, ut de re tam luctuosa compendium sectetur" donde queda patente el interés del legislador por tutelar o defender los intereses de quienes sufrían la pérdida de la nave y su contenido. PURPURA, G. Relitti di navi e diritti del fisco. pp. 18 yss. PINZONE, op. cit. p. 67 y ss.
} 
nec fit adprehendentis, quia pro derelicto non habetur ${ }^{19}$ ", sino el interés por salvar la integridad de la nave y el resto de las mercancías, salvo reconocimiento expreso del titular al haber perdido cualquier esperanza de recuperación, en cuyo caso, sería legítima la apropiación por el hallazgo. En palabras de Javoleno 11 ex. Cass., D. 41.1.58²:

"Quaecumque res ex mari extracta est, non ante eius incipit esse qui extraxit, quam dominus eam pro derelicto habere coepit”.

Antes de proceder al análisis y estudio de la situación jurídica de los bienes tras un incidente marítimo, debemos recordar que existe una obligación legal de asistir y auxiliar a aquellos que se encuentren en situación de peligro, con riesgo de pérdida de mercancías y de la nave ${ }^{21}$, tutelado con la imposición de las penas prevista por la Lex Corneliae para los sicarios, aparece recogido en la segunda parte del fragmento de Ulpiano 56, ad. Ed. en D. 47.9.3.8:

“.... item alio Senatusconsulto cavetur, eos, quorum fraude aut consilio naufragi suppresi per vim fuissent, ne navi vel ibi periclitantibus opitulentur, legis Corneliae, quae de sicariis lata est..."

Del contenido íntegro del texto, y siguiendo a ZAMORA22, podemos afirmar que se tutelan los actos de latrocinio o expolio realizados con ocasión de un naufragio. De ahí que se establezcan las penas existentes y conducentes a perseguir la falta de asistencia y auxilio, así como los posibles actos de rapina cometidos tras un naufragio, donde entraría en juego la Lex Cornelia, encargándose de regular dichas sanciones, legis Corneliae, quae de sicariis lata est, poenis adficiendos ${ }^{23}$.

Procediendo al análisis sucinto de algunos textos jurídicos que se pronuncian sobre la tutela de la propiedad y de los bienes, la prohibición de la direptio ex naufragio, y expresamente sobre el naufragio, podemos extraer las siguientes conclusiones.

En primer lugar, vemos cómo se prohíbe la adquisición por prescripción adquisitiva de los bienes encontrados en el mar como consecuencia del incidente de naufragio, según la disposición dada por Javoleno 7 ex.

\footnotetext{
${ }^{19}$ Paulo 34, ad. Ed., D.14.2.2.8. Las cosas alijadas no pueden ser objeto de ocupación, debiendo ser restituidas a sus legítimos propietarios, porque no se puede presumir que se arrojan las mismas con la intención de renunciar a la propiedad, sino con la finalidad de salvar la nave y el resto de la carga. En idéntico sentido se pronuncia Juliano ex Min., D.14.2.8: "Qui levandae navis gratia res aliquas proiiciunt, non hanc mentem habent, ut eas pro derelicto habeant..." y Gayo 2, res. Cott., D.41.1.9.8 "quae in tempestate maris levandae navis causa eiiciuntur; hae enim dominorum permanent, quia non eo animo eiiciuntur..."

${ }^{20}$ BURDESE, A. In tema de res derelictiae, BIDR, 1989, p.630. En palabras del autor, la pérdida de la propiedad es automática desde que el abandono es definitivo, independientemente de que haya habido o no declaración de voluntad en ese sentido. Por su parte, VACCA, L., "Derelictio" e acquisto delle "res pro derelictio habitae", Lettura delle fonti e tradizione sistematica, Milán, p.55. condiciona la ocupación por derelictio de res mancipi y nec mancipi a la certeza del abandono del propietario y la posibilidad de poder probarlo en sede judicial.

${ }^{21}$ MATAIX FERRÁNDIZ, E., La nave como unidad jurídica en Derecho romano: Algunas reflexiones en torno a D.47.9.3.8 (Ulp.56 ad. Edict) en la Actividad de la Banca y los negocios mercantiles en el Mare Nostrum, 2015, pp.525-540. Analiza en su estudio el concepto de nave entendido como un todo orgánico, destacando que todo daño que afecte a una parte de la nave o algunos de sus elementos, es concebido como un ataque a la integridad de la nave en su conjunto.

${ }^{22}$ Véase ZAMORA MANZANO, José Luis, “El Salvamento y la Asistencia Marítima en el derecho romano”, Rida 48, 2001, pp. 373-403
} 
Cass., y contenida en D. 41.2.21.1 "Quod ex naufragio expulsum est, usucapi non potest, quoniam non est in derelicto, sed in deperdito", que relacionamos con D.41.2.21.2, donde se prohíbe no sólo la apropiación ilegítima de los bienes hundidos sino también los arrojados al mar para salvar la nave, al interpretar la voluntad del propietario y entender que en tales circunstancias no existe animus dereliquendisino intención de conseguir un resultado útil, como es la salvación de la embarcación y el resto de mercancías que se hallen en la misma "quoniam non potest videri id pro derelicto habitum, quod salutis causa interim dimissum est".

Por su parte, Juliano 2 ex. Min., D. 41.7.724, en la misma línea argumental, reconoce que no pueden ser usucapidas las cosas arrojadas, porque no se consideran abandonadas; Gayo 2 res. Cott., D.41.1.9.8²5, no sólo reconoce el derecho de propiedad en los casos de alijo, sino que advierte el carácter delictivo de tales apropiaciones; Paulo 3, epit. Alf. recogido en D.14.2.7, que tutela el derecho a la propiedad de las mercancías recuperadas tras un naufragio, por su legítimo titular, "cum depressa navis aut deiecta esset, quod quisque ex ea suum servasset, sibi servare respondit, tamquam ex incendio"; Ulpiano 19, ad. Ed. en D.41.1.44 que prohíbe la ocupación, estableciendo una sanción consistente en el cuádruplo del valor del bien, para aquellos que contravengan dicho principio, "et si naufragio quid amissum sit, non statim nostrum esse desinere; denique quadruplo teneri eum, qui rapuit", no pudiendo obviar el contenido del edicto del emperador Adriano ${ }^{26}$, que pone de manifiesto la prohibición de direptio ex naufragio, considerando robo la apropiación ilegítima de bienes procedentes de naves varadas, encalladas o hundidas, por quienes tuvieran la posesión de bienes en la orilla.

La consolidación del principio del respeto a la propiedad de los bienes naufragados y la protección y tutela sobre los mismos, se configuró de un modo paulatino a medida que se iba superando la concepción primitiva de la institución, que permitía los actos de apropiación, las expoliaciones y despojos sobre los bienes, como hemos indicado, hasta ser considerado un elemento nuclear en la configuración de la regulación marítima de la antigua Roma.

\footnotetext{
${ }^{23}$ PINZONE A, "Naufragio, fisco e transporte marittimi nell'eta di Caracalla (Su C.I.11.6.1)” en Quaderni Catanes di Studi Classici e Medievali, 4, 1982, 78 y ss.

${ }^{24}$ D. 41.7.7: "Si quis merces ex nave iactatas invenisset, num ideo usucapere non possit, quia non viderentur derelictae, quaeritur; sed verius est, eum pro derelicto usucapere non posse".

${ }^{25}$ D.41.1.9.8 " ... quae in tempestate maris levandae navis causa eiiciuntur; hae enim dominorum permanent, quia non eo animo eiiciuntur, quod quis eas habere non vult, sed quod magis cum ipsa nave periculum maris effugiat; qua de causa si quis eas fluctibus expulsas vel etiam in ipso mari nactus lucrandi animo abstulerit, furtum committit"

${ }^{26}$ Recogido por Calístrasto 2, Quaest. en D. 47.9.7
} 


\section{LA INFLUENCIA DEL DERECHO ROMANO SOBRE EL CONVENIO DE NAIROBI DE 2007}

En las siguientes líneas vamos a tratar de dilucidad algunas referencias en relación a preceptos del CNRRN que casan o guardan relación con la experiencia jurídica romana y sus fuentes, sin ánimo de profanar la relación tiempo y Derecho o en un presentismo irreal.

El Convenio Internacional de Nairobi, sobre la Remoción, además de establecer una regulación para la extracción de restos de naufragio, hace mención a situaciones que tienen lugar inmediatamente acaecido el incidente, así como a aquellas que se suceden en el período de tiempo que transcurre desde el naufragio hasta la efectiva remoción de los restos.

Respecto al momento inmediatamente posterior al naufragio, el artículo 5 del Convenio, establece que los Estados partes se obligan a exigir a sus armadores y capitanes, a informar sin demora al Estado cuando su buque haya estado implicado en un siniestro marítimo que haya ocasionado restos de naufragio, estableciendo el texto, la necesidad de que dicha declaración, incluya información detallada que pueda servir al Estado afectado para precisar si los restos del naufragio constituyen un riesgo para la navegación. En particular, el citado informe debe describir la ubicación exacta de los restos, el tipo, tamaño y construcción de los mismos; la naturaleza de los daños y estado; la naturaleza de la carga y cantidad, así como especificar, si el buque contiene sustancias nocivas o potencialmente peligrosas e hidrocarburos.

Encontramos un antecedente que guarda similitud en el Derecho Romano, así los armadores de la nave que se dedicaban al transporte de alimentos y de mercancías, en caso de accidente con pérdidas, daños en la nave o en la carga, debían hacer una declaración -relatio ${ }^{27}$ - sobre el suceso acaecido y sobre las posibles causas del mismo, la cual tenía un procedimiento determinado y específico, denominado de naufragiiis ${ }^{28}$.

Dicho deber de comunicación, aparece reflejado en una Constitución de los Emperadores Valentiniano, Valente y Graciano, del año 372 d.C recogida en el C.1 1.6.2 dirigida al Prefecto del Pretorio:

\footnotetext{
${ }^{27}$ Una constitución dada por los emperadores Honorio y Teodosio, recogida en C.11.6.6 (409) establece que cuando se trate de un naufragio fortuito, no es necesario realizar la comunicación del accidente puesto que la culpabilidad no sería atribuible a ninguno de los agentes de la navegación.

${ }^{28}$ El deber de comunicar a la autoridad competente los descubrimientos, se conserva en obras de derecho intermedio como la Nueva Recopilación en la Ley II, Tit.XIII, libro VI y en la Novísima Recopilación en la Ley, Tit. XXII, libro X. En la actualidad, la Ley de Navegación Marítima impone la obligación al capitán de poner en conocimiento aquellas incidencias cuya comunicación resulte obligatoria y aquellas que considere bajo su criterio, a la Capitanía marítima del puerto de destino y si fuera extranjero al cónsul español o la autoridad local, y en defecto de las anteriores ante notario o fedatario público. Asimismo, debe dejar constancia de lo sucedido en el Diario de Navegación y declarar los hechos dentro de las 24 horas hábiles siguientes a su llegada a puerto de destino. Si se tratase de hechos por los que se pudiera deducirse la responsabilidad del capitán, éste podrá levantar lo que se conoce como protesta de mar; para lo cual deberá redactar un acta en el que hace constar todo lo sucedido tal y como aparece redactado en el Diario de Navegación y entregar copia compulsada de la protesta y del Diario a todos los interesados. Vid. Art. 186 y 187 de la LNM, así como el art. 504 del mismo cuerpo legal.
} 
"Si quis navicularius naufragium sustinuisse adfirmat, provinciae iudicem, eius videlicet, in qua res agitur, adire festinet ac probet apud eum testibus eventum, relatioque ad sublimissimam referatur praefecturam, ita ut intra anni spatium veritate revelata competens dispositio procedat ${ }^{29}$. Quod si per neglegentiam praefinitum anni spatium fortasse claudatur, supervacuas serasque interpellationes emenso anno placuit non admitti”.

Del texto se infiere, la obligatoriedad de acudir en caso de naufragio al juez del lugar donde se ha realizado el negocio ${ }^{30}$, para comunicar el accidente sufrido ${ }^{31}$ y probar mediante testigos la veracidad de los hechos que testimonia -veritate revelata-. Dicha declaración, debe realizarla el navicularius en un plazo máximo de un año ${ }^{32}$, destacando que, transcurrido dicho período sin que hubiera tenido lugar la comunicación, se pierde la posibilidad de quedar exonerado de toda responsabilidad por el siniestro.

Mediante ese trámite, la autoridad ${ }^{33}$ aceptaba la veracidad de los hechos relatados, iniciaba un procedimiento de investigación, y a su conclusión, adoptaba medidas disciplinarias, responsabilidad civil y/o sanciones penales contra el magister ${ }^{34}$ y el exercitor navis ${ }^{35}$.

\footnotetext{
${ }^{29}$ SOLAZZI, S., Su C. I. 11. 6 De naufragiis, in Scritti Diritto Romano, 4, Nápoles, 1963, p.167. Con la expresión competens dispositio procedat, se evidencia que la comunicación del siniestro persigue la investigación y la posterior determinación de responsabilidad, independientemente, de si el transporte se realizaba por un empresario privado o por un navicularius al servicio del Estado. Por su parte, una constitución dada por los emperadores Valentiniano, Valente y Graciano al prefecto del pretorio recogida en C. Th.13.9.1 (372), con la manifestación "veritate relata remedium ex indulgentia consequatur", parece exigir la protesta y la investigación del naufragio cuando el transportista estuviera al servicio del Estado, para exonerar a aquel de toda responsabilidad por el siniestro, cuando se tratara de un naufragio fortuito, y no para la investigación y posterior depuración de responsabilidades.

${ }^{30}$ Según Manfredini, la competencia jurisdiccional la ostenta el juez más próximo al lugar en donde se produce el accidente. «Le navicularius, pour ne pas ocurrir le risque de devoir payer la cargaison, doit dénoncer le naufrage et le prouver par de témoins chez le iudex provinciae (c'est-à-dire le recteur de la provincie la plus procge du lieu du naufrage) » MANFREDINI, D., Les naviculaires et le naufrage, RIDA 33, 1986, p.136.

${ }^{31}$ Partiendo de lo descrito por Marciano, De Delat., contenido en D.39.4.16.8, entendemos que la comunicación de la echazón de los bienes al mar por tempestad, al margen de ser obligatoria para garantizar que no existe fraude y el accidente no ha sido doloso, se produce con la intención de evitar el decomiso de los bienes por el fisco, rompiendo con la regla general aplicada por los publicanos, de exigir el pago del impuesto desde el momento en el que las mercancías toman tierra. La superación de la concepción primitiva del ius naufragii implicó el reconocimiento y la tutela del derecho a la propiedad de los bienes naufragados, frente a cualquier acto de latrocinio, despojo o potestad atribuida al fisco como enunciamos en el texto de Marciano y como se describe en una Constitución dada por el emperador Antonino a Máximo recogida en C.1 1.6.1 "quando naufragio navis expulsa fueris ad littus, vel si quando reliquam terram attigerit, at dominos pertineat; fiscus meus sese non interponat"

${ }^{32}$ El Código Teodosiano recoge una Constitución (372-375) dada por los emperadores Augusto y Demetriano dirigida a los prefectos de la annona en África, donde admite en el caso de viajes largos o dirigidos hacia Constantinopla que el período para formalizar la denuncia sea de dos años. C.Th.13.9.2 "... intra annum quidquid acciderit iudiciis publicetur, de his vero, quae ad portus expeditionales longius vel constantinopolim sint profectae, intra biennium ..."

${ }^{33}$ Durante los primeros siglos, la legislación originaria parecía imponer el deber de comunicación a los navicularii publicas species transportantes, y la praefectura (C.Th. 13.9.5) era la encargada de recibir la relatio, de efectuar la investigación y de decidir sobre la absolución o la condena. Se trataba, en todo caso, de una autoridad investida de la administración de justicia, y cuya intervención en el procedimiento de investigación, garantizaba una correcta aplicación de las normas, al tutelar y velar por los intereses estatales. Posteriormente, Justiniano reconoce derecho a todos los empresarios marítimos, extendiendo el procedimiento de investigación a todas las naves, de modo que la investigación no se atribuía exclusivamente a un funcionario público sino al competens iudex. VIDALI D. Saggio critico sull 'accertamento del sinistro de mare nel diritto romano. Dir. Mar., 1936, p. 251. SOLAZZI, S., Su C. I. 11.6, De naufragiis ..., p.258.

${ }^{34}$ ROUGÉ, Jean., Recherches sur la l'organisation du commerce maritime en méditerranée sous l'empire romain. París, 1966, p. 237, lo define como un agente comercial del propietario o el armador: "est un agent comercial du propiétaire ou de l'armateur du navire et que l'on ne peut absolument pas accepter la thése qui prédomine a I 'heure actuelle chez les historiens du droit romain et
} 
Una vez realizadas las operaciones descritas anteriormente, el propietario de los bienes inscritos está obligado por sí mismo a la remoción ${ }^{36}$ de los restos ${ }^{37}$ naufragados que se haya determinado que constituyen un riesgo, o contratar a un tercero para que realice tales operaciones, con las limitaciones que el Estado afectado le imponga por razón de seguridad y protección del medio marino, con carácter previo o una vez iniciadas las mismas.

No obstante, a pesar de que no podamos hablar en Derecho Romano de la remoción de restos tal y como aparece configurado en la actualidad, podemos afirmar que las fuentes romanas, imponen al titular de las mercancías arrojadas al mar para salvar la nave, el deber de iniciar las labores de búsqueda y la recuperación de las mismas si conocen el lugar en el que fueron alijadas, según lo dispuesto por Juliano 2 ex. Min. D. 14.2.8 "et si suspicati fuerint, in quem locum eiectae sunt, requisituros ut perinde sint'. No obstante, nada impide que terceros, que no guarden relación con el titular de los bienes, puedan proceder a la recogida y la extracción de bienes naufragados, puesto que como vimos, se reconoce la licitud de tales operaciones.

Ahora bien, hablamos de la licitud de la recuperación de bienes perdidos a raíz de un incidente en la navegación que obliga al alijo de las mercancías, o como consecuencia del incidente de naufragio, y no de los actos de expoliación y despojo resultante del ataque a las naves.

Procediendo con el análisis del CNRRN, en relación con los aspectos que guardan coincidencias con fuentes jurídico romanas, el artículo 9.2 del Convenio, que se inserta dentro del título, "Medidas para facilitar la remoción de restos de naufragio", dispone que una vez informados el Estado de la matrícula del buque y el propietario inscrito, de la existencia de restos de naufragio, "el propietario inscrito procederá a la remoción de los restos de naufragio que se haya determinado que constituyen un riesgo", o bien puede "contratar a un salvador o a otra persona para que se encargue de la remoción de los restos de naufragio", al amparo de lo dispuesto en el artículo 9.4, destacando que si las medidas adoptadas se consideran operaciones de salvamento de conformidad con la legislación nacional, dicha normativa será de aplicación a las cuestiones de remuneración o indemnización de los salvadores ${ }^{38}$. En ese sentido, destacar que en los supuestos de salvamento, remuneración y asistencia a los salvadores en el Estado Español, nos debemos remitir a lo dispuesto en el Convenio Internacional sobre

qui veunt que le magister soit le capitaine du navire". GABALDON GARCÍA, J.L - RUIZ SOROA, J.M., Manual de derecho de la Navegación Marítima, Madrid, 2006, p. 401.

${ }^{35}$ COPPOLA BISAZZA, G., Ancora una parola sull' exercitor, IURA 54, 2003, pp. 130-136.

${ }^{36}$ Art. 1.7 del CNRRN

${ }^{37}$ Art. 1.4 del CNRRN

${ }^{38}$ Con carácter general, el propietario se presenta como el responsable de todos los costes anteriores y posteriores a la remoción de los restos. Pero tal responsabilidad se encuentra matizada por un régimen de excepciones a la responsabilidad previstas en el artículo 10.1 y 11 del Convenio, y por un genérico reenvío a regímenes de limitación de responsabilidad según el apartado 2 del artículo 10. Una de las excepciones es la inaplicabilidad del Convenio cuando las medidas adoptadas tengan la consideración de operaciones de salvamento. 
Salvamento Marítimo (CISM) de Londres de 1989, de 28 de abril, recogido posteriormente en la Ley 14/2014, de 24 de julio, de Navegación Marítima, que condiciona el pago del premio a la existencia de un resultado útil, salvo en los supuestos de salvamento obligatorio u operaciones de salvamento para la protección del medio ambiente, que dan derecho a exigir el pago al titular de los bienes aun cuando no hayan conseguido el resultado útil, reconociendo el derecho a exigir al propietario el abono de los gastos en los que hubiera incurrido.

Al margen de tales consideraciones, la LNM en el art. 362.1, sigue el principio anglosajón no cure no pay, previsto también en el art. 12.1 del CISM, en tanto que exige la superación de la situación de peligro o una minoración de los daños, para tener derecho al "premio", que no podrá exceder del valor del buque ni de las mercancías salvadas, y se reparte entre el armador del buque salvador y su dotación en la proporción de un tercio y dos tercios respectivamente ${ }^{39}$. La fijación del premio encuentra su base legal en los criterios de determinación establecidos en el art. 1.3 del CISM, que destaca los riesgos en los que pudieran incurrir los salvadores, la naturaleza y el grado de peligro, el tiempo empleado, los gastos y pérdidas sufridas, la preparación y eficacia del salvador, la pericia y, por supuesto, el resultado obtenido.

De forma análoga, en el ordenamiento jurídico romano, se impone el deber de recuperar los bienes perdidos o hundidos, por sí mismos, tal y como se impone en D.14.2.8 o por la acción de profesionales en virtud de una relación contractual. En ese sentido, habiéndose producido un incidente en la navegación, Calístrato 2 Quast. D.14.2.4.1 ${ }^{40}$ dispone que se procede a la recuperación y/o extracción de la carga hundida mediante la intervención convenida o pactada de los urinatores ${ }^{41}$, a cambio de una renta o merces "urinatores extractae sunt data mercede rationem haberi debere eius". Ahora bien, aun cuando el texto evidencia la existencia de un vínculo contractual entre las partes y el reconocimiento del pago de una merces por la recuperación o extracción de las mercancías por el urinator, no podemos determinar basándonos en esta disposición, el valor de la misma ni los criterios que se han tenido en cuenta para su fijación. Para ello, debemos apoyarnos en un texto de los Basílicos

\footnotetext{
${ }^{39}$ Vid. art. 363 LNM.

${ }^{40}$ LENEL, O., Palingenesia Iuris Civilis, vol. 1, Graz, 1960, p. 102 \$ 98. Calístrato 2 Quast. D.14.2.4.1 "Sed si navis, quae in tempestate iactu mercium unius mercatoris levata est, in alio loco summersa est, et aliquorum mercatorum merces per urinatores extractae sunt data mercede rationem haberi debere eius, cuius merces in navigatione levandae navis causa iactae sunt ab his, qui postea sua per urinatores servaverunt, sabinus aeque respondit. Eorum vero, qui ita servaverunt, invicem rationem haberi non debere ab eo, qui in navigatione iactum fecit, si quaedam ex his mercibus per urinatores extractae sunt: eorum enim merces non possunt videri servandae navis causa iactae esse, quae perit".

${ }^{41}$ V. Urinatores: plongeur v. DAREMBERG-SAGLIO, V. Urinator. Dictionnaire des Antiquités grecques et romaines, Vol. V, Paris 1877-1919, p.604,HEUMAN SECKEL, v. urinator, Handlexicon z.d, Quellem des Römischen Rechts, 1914, 604, ERNOUT- MEILLET, Dictionnaire étym, langue latine, París, 1959, p. 755, GLARE, P.G.W, V. urinator-urinor (buceador), Oxford latin dictionary, volumen II, 1982, reimp. 2012, p.2323. V. urinare v. KENT, R, Varro on the latin language, 5.27.126, V.II., 1967, p. 121, VARRO, Ling. 5.27.126, "Praeterea erat tertium genus mensae item quadratae vasorum; vocabatur urnarium, quod urnas cum aqua positas ibi potissimum habebant in culina. Ab eo etiam nunc ante balineum locus ubi poni solebat urnarium vocatur. Urnae dictae, quod urinant in aqua haurienda ut urinator. Urinare est mergi in aquam". En la glosa al D.14.2.4.1,
} 
encuadrado en el título 8 del libro 53, donde se comenta y se introducen aspectos no previstos en el libro 14 del Digesto sobre la Lex Rhodia de iactu.

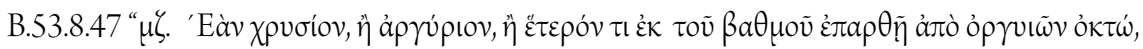

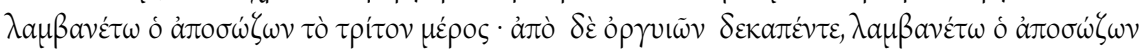

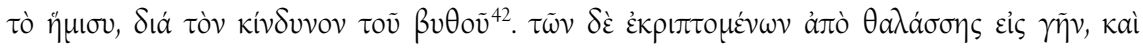

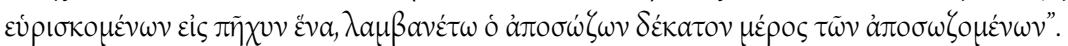

Este fragmento de los Basílicos introduce un elemento de valoración del riesgo y de la actividad realizada por los salvadores que no había sido contemplada en las fuentes jurídico romanas, y es, la profundidad a la que se sumergen los profesionales para la extracción de los bienes, y el peligro de tales operaciones ante las limitaciones técnicas existentes.

En ese sentido, y partiendo del fragmento, si los bienes extraídos se encuentran a una profundidad de ocho codos, corresponde al urinator una tercera parte de los mismos; y si se sumerge quince codos, reconocen las fuentes el derecho a exigir la mitad ${ }^{43}$. Si partimos de la literalidad del fragmento, debemos entender que se le atribuye al salvador una tercera parte o la mitad de las mercancías recuperadas. No obstante, consideramos que es lícito interpretar que se pudiera convenir con el salvador en concepto de remuneración, el importe del valor de los bienes, aplicando extensivamente lo dispuesto por Paulo 34 ad. Ed. D.14.2.2.444, para la regulación de la estimación y valoración de las averías en los supuestos de contribución por pérdidas de las mercancías. El problema de determinar la retribución en función del valor de las mercancías se produce cuando las mercancías devienen inservibles, en cuyo caso, creemos que al tratarse de un contrato consensual, las partes pudieron partir del criterio establecido en los Basílicos, y pactar las condiciones del pago de la renta en los supuestos de deterioro, o bien, disponer una cuantía fija, por la mera prestación del servicio, y una variable que estaría en función del valor del bien tras la recuperación. Todo ello, sin perjuicio del derecho que le asiste a retener las mercancías en los casos de incumplimiento contractual.

La exigencia de un resultado útil, entendida como la efectiva recuperación de los bienes, podía ser considerado como el precedente del principio anglosajón no cure no pay, que exige la salvación, de todo o parte, de los bienes para exigir el abono de la remuneración por la prestación del servicio de salvamento.

encontramos esta referencia respecto a la figura de los buceadores "Urinatores dicuatur, natatores fubaquatiles: quos ita Latinè dici volút ab vrna, cùm in aquam mergitur".

${ }^{42}$ La edición que manejamos de los Basílicos es HEIMBACH G.E, Basilicorum Libr. LX, t.5, LIPSIAE, 1850, p. 127 cotejada con SCHELTEMA H,J-VAN DER WAL, Basilicorum libr, LX, v.7, Groningen, 1974, p. 2479 que sigue la estructuración de FERRINI, E.C- MERCATI, J., Basilicorum libr, LX, v. 7, Lipsiae, 1897, p. 119; donde no se aprecian cambios sustanciales en el texto.

${ }^{43}$ La Ley de Navegación Marítima, en el art. 363, destaca que el importe de la recompensa no puede exceder del valor del buque ni de las mercancías salvadas, y se reparte entre el armador del buque salvador y dotación en la proporción de un tercio y dos tercios respectivamente.

${ }^{44}$ Paulo 34 ad. Ed. D.14.2.2.4: "Portio autem pro aestimatione rerum quae salvae sunt et earum quae amissae sunt praestari solet, nec ad rem pertinet, si hae quae amissae sunt pluris veniri poterunt, quoniam detrimenti, non lucri fit praestatio. Sed in his rebus, quarum nomine conferendum est, aestimatio debet haberi non quanti emptae sint, sed quanti venire possunt". 
Al mismo tiempo, partiendo de la definición que el Convenio realiza sobre el concepto de remoción, creemos oportuno traer a colación, como anunciamos al inicio, las actividades de prevención, reducción o eliminación del riesgo que realizaban los scaphari en el mar o en los ríos mediante el empleo de naves de menor tamaño denominadas scapha. Parafraseando a Rougé ${ }^{45}$, las grandes embarcaciones disponían de barcas a remo ubicadas en la parte trasera o en la cubierta, que podían servir de botes salvavidas en los casos de naufragio.

Profundizando en las funciones que realizaban, debemos señalar que al igual que los urinatores, destacaron por su intensa actividad portuaria y en las operaciones de asistencia y salvamento, lo que favoreció la constitución de cuerpos profesionales según atestiguan las diversas inscripciones epigráficas que ponen de manifiesto la existencia de asociaciones profesionales de barqueros o scaphari en el puerto de Ostia ${ }^{46}$ y también en Hispania, en la zona de la Bética y en la ciudad de Sevilla, atraídos por la posibilidad de ganancias mercantiles al servicio de la annona.

Su actividad principal consistía en la asistencia a buques de gran tonelaje y con bastante carga a bordo, tanto en las llegadas como en las salidas de los ríos o de los puertos, en los casos de peligro, aligerando las naves del peso de las mercancías para favorecer las maniobras de atraque en el puerto ${ }^{47}$, o el remolque ${ }^{48}$ a las orillas en los supuestos de accidente. Por otro lado, en los casos de naufragio, varada o encalladura de la nave, favorecían el descenso de los pasajeros y los trasladaban hasta la orilla. . ${ }^{49}$

Por el desarrollo de estas funciones, los scapharipercibían una remuneración que consistía en una quinta parte de las mercancías recuperadas o el valor de las mismas si adoptamos el mismo criterio que para la retribución de los urinatores, como queda atestiguado en un texto de los Basílicos, que hace referencia a la necesidad de la intervención de los barqueros, mediante la prestación de auxilio a las naves afectadas o dañadas por la fuerza del mar o fenómenos marítimos adversos, para asegurar la integridad de la nave y los bienes contenidos en la misma.

\footnotetext{
${ }^{45}$ ROUGÉ, Recherches sur ...p. 48-49

${ }^{46}$ CIL 14.409= Orelli 4109 “... item corpor(atorum)-scaphariorum et lenuncularior(um) trayecto(us) Luculli et dendrophorum et togato(rum) a foro et de sacomar(is) ..." A diferencia de las corporaciones profesionales existentes en Hispania, los cuerpos de scaphari que operaban en Ostia no parecen haber estado adscritos a un puerto determinado de modo que podían desarrollar su actividad indistintamente en uno u otro puerto.

${ }^{47}$ En la actualidad, la LNM reconoce esta actividad bajo la forma del contrato de practicaje, que se define como aquel en virtud del cual un práctico, a cambio de una remuneración, se obliga a prestar asesoramiento al capitán en la realización de las operaciones y maniobras de los buques o las realiza por sí mismo. (art. 325 a 328)

${ }^{48}$ FESTUS, v. remulco="remulco dicitur quum scaphae remis navis magna trahitur" p. 346. v. promulco= "agi dicitur navis, cum scaphae ducitur fune”, Lindsay, 1965, p.244. Vemos como ambos términos tienen significados análogos y se emplean para referenciar el acto de remolque. La LNM distingue tres modalidades de contrato de remolque, siendo el remolque de fortuna, el que mas se asemeja a la actividad de asistencia que desarrollaban los scaphari en los puertos, en tanto que se presta en supuestos extraordinarios que no llegan a constituir un salvamento, y que se realizan para evitar daños en las naves, art. 305 LNM.

${ }^{49}$ DE SALVO, Economia private e publici servizi ...p. 269 -271. Hace mención a una epístola de San Paulino de Nola, que cuenta la historia de un navicularii denominado Valgio, que pasa 23 días a la deriva en una embarcación después de que fuera abandonado por el resto de la tripulación, que tras un accidente, logra salvarse lanzándose al mar en una scapha integrada en la nave que sufrió la
} 


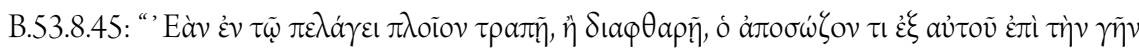

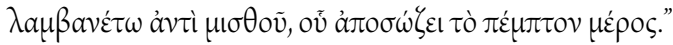

"si navis in mari correpta vorticibus aut corrupta fuerit, qui aliquid in terram ex ea salvum exportat, mercedis loco rei conservatae quintam partem consequatur."

Por lo que respecta a la responsabilidad del titular, el artículo 10 del Convenio establece como regla general, que el propietario inscrito es quién debe asumir los costes de la localización, balizamiento y remoción de los restos del incidente, a menos que acredite que el siniestro marítimo que dio lugar a los restos del naufragio es el resultado de enfrentamientos armados o de fenómenos naturales excepcionales, inevitables e irresistibles, consecuencia de la acción u omisión de un tercero que actuó con la intención de causar un daño, o por último, que haya acaecido por la negligencia o una acción lesiva de otra índole de cualquier Gobierno o autoridad responsable del mantenimiento de las luces u otras ayudas a la navegación, en el ejercicio de esa función.

En Roma, la actividad comercial por mar, no estaba exenta de riesgos ni de peligros que podían afectar en mayor o menor medida a la nave, a las mercancías o a los interesados en la aventura marítima. Esos riesgos, que en ocasiones se convierten en accidentes, podían tener lugar por la acción propia del hombre, como ocurría con el naufragio por simulación del falso faro ${ }^{50}$, por actos de expugnación o depredación por los violentos ataques ${ }^{51}$, por omisión de auxilio ${ }^{52}$, por impericia del capitán ${ }^{53}$, o el falso naufragio ${ }^{54}$, o por inclemencias meteorológicas. Como vemos, incidentes en la navegación reconocidos por las fuentes romanas, que sirven para delimitar y configurar el régimen de responsabilidades del propietario de las mercancías en las disposiciones contenidas en el Convenio de

contingencia. Traemos a colación este fragmento para reconocer la importancia de las scapha en las operaciones de salvamento de pasajeros tras un incidente.

${ }^{50}$ La simulación de falso faro, era una práctica llevada a cabo por los propietarios de fundos ribereños o de pueblos cercanos a la costa, para provocar la confusión del capitán de la nave y acercarla a la orilla o las riberas de los ríos, y favorecer con ello, la apropiación de la carga contenida en la misma. El paradigma lo encontramos en Ulpiano 1, Op., D.47.9.10, "ne piscatores nocte lumine ostenso fallant navegantes, quasi in portum aliquem delaturi, eoque modo in periculum naves, et qui in iis sunt, deducant, sibique execrandam praedam parent, praesidis provinciae religiosa constantia efficiat".

${ }^{51}$ Ulpiano 56 ad. Ed., D.47.9.3.1: "Rate, navi expugnata; expugnare videtur, qui in ipso quasi proelio et pugna adversus navem et ratem aliquid rapit, sive expugnet, sive praedonibus expugnantibus rapiat"

${ }^{52}$ El senadoconsulto Claudiano reunido en una parte del fragmento de Ulpianus 56 ad Ed, D. 47.9.3.8, imponía el deber de prestar auxilio a las naves que se encontraran en peligro y a la tripulación so pena de deportación, privación de todos los bienes o la muerte. ${ }^{53}$ Existen referencias en el Digesto que evidencian los supuestos en los que una falta de diligencia provoca el incidente del naufragio o la pérdida de la nave y de los bienes objeto del transporte. Un primer supuesto, lo encontramos en un fragmento de Ulpiano 32 ad. Ed, contenido en D.19.2.13.1: "Si navicularius onus Minturnas vehendum conduxerit, et, cum flumen Miturnense navis ea subire non posset, in aliam navem merces transtulerit, eaque navis in ostio fluminis perierit, tenetur primus navicularius; Labeo, si culpa caret, no tenere ait, ceterum si vel invito domino fecit, vel quo non debuit tempore, aut si minus idoneae navi, tunc ex locato agendum”. Por otra parte, Ulpiano 32, ad. Ed. en D.19.2.13.2, nos plantea el supuesto en el que iniciada la expedición, el magíster deja a la nave sin gobierno, al no colocar al gubernator en la dirección de la nave durante la navegación por un río, provocando de un modo indirecto el hundimiento o la pérdida de la nave: "Si magister navis sine gubernatore in flumen navem immiserit, et tempestate orta temperare non potuerit, et navem perdiderit, vectores habebunt adversus eum ex locato actionem”.

${ }^{54}$ Algunos transportistas aprovecharon la asunción del riesgo por parte del gobierno romano, para cargar mercancías de escaso valor en naves viejas y provocar el hundimiento voluntario de las mismas, con la finalidad de percibir una indemnización por los daños, al haber puesto en conocimiento de la autoridad competente el incidente y un volumen de pérdidas muy superior a las verdaderamente sufridas PURPURA, G., Il naufragio nel diritto romano: problemi giuridici e testimonianze archeologiche, in Annale Università di Palermo, 1995, pp.465-476. 
Nairobi que estamos analizando.

Por lo que respecta a los accidentes en la navegación y el posterior hundimiento de la nave, debemos distinguir por un lado la responsabilidad objetiva, inherente al contrato de transporte, por la que se obliga al transportista a la conservación y entrega de las mercancías, o responder por los daños o las pérdidas sufridas al terminar la expedición marítima, y por el otro, la obligación de proceder a la remoción de los restos naufragados que corresponde al propietario de los bienes.

En el primero de los casos, en los supuestos de naufragio, las fuentes romanas exoneran de responsabilidad al navicularius, en los casos de naufragio fortuito ${ }^{55}$, es decir, cuando el incidente haya tenido lugar por inclemencias meteorológicas, por la colisión incidental con otra nave que ha perdido el gobierno sin que pueda imputarse impericia al gubernator navis o capitán de la nave, o por la acción dolosa de terceros. En contraposición, fuera de estos supuestos, comunicado el accidente, se procede a la investigación del naufragio que persigue no sólo el esclarecimiento de los hechos, sino también la determinación civil o penal atribuible a los responsables, puesto que al término de la investigación, el juez debe pronunciarse sobre la absolutio o la condemnatio del naviculariusy demás agentes de la navegación.

En relación a la responsabilidad del propietario de los bienes, destacar, que por razones obvias, no se le podía exigir la asunción de los costes correspondientes a la localización y balizamiento del naufragio, pero sí, como ha quedado constatado cuando analizamos lo dispuesto en D. 14.2.8, existía la obligación legal del propietario, de realizar las labores de búsqueda y la remoción de los restos del naufragio si conocían el lugar donde habían sido alijadas, entre otros aspectos, por la superación del ius naufragii, respetando y tutelando el derecho de propiedad, no aplicando el principio general de abandono que convierte al bien en una res nullius y considerando que tanto en la echazón como en el hundimiento, no queda acreditada la intencionalidad del legítimo propietario de abandonar las mismas, res autem iacta domini manet, nec fit adprehendentis, quia pro derelicto non habetur, sino el interés por salvar la integridad de la nave y el resto de la carga.

\section{NOTA CONCLUSIVA}

En el desarrollo del estudio hemos podido comprobar la influencia del derecho romano en la

\footnotetext{
${ }^{55}$ En Roma, hablamos de naufragio fortuito para referirnos a aquel accidente que tiene lugar cuando se produce el hundimiento de la nave como consecuencia de fenómenos meteorológicos adversos como temporales o tormentas impredecibles o que siendo previsibles sean inevitables y no se produzcan en los meses poco propicios para la navegación -Susceptionis autem necessitas ex Kalendis Aprilis in diem Kalendarum Octobris mansura servabitur-, excepto cuando se incentiva la prestación del servicio de transporte fuera de estos períodos, en cuyo caso, se exonera al navicularius de toda responsabilidad al ser asumida la misma por la annona. Al mismo tiempo, hablamos de los supuestos en los que tiene lugar el arribo forzoso de la nave, o su hundimiento por el ataque sufrido por terceros mediante el empleo de la violencia y la fuerza, según dispone Calístrato 1, Ed. Monit., en D. 47.9.6 y Ulpiano 56 ad. Ed., D.47.9.3.1. Vid. DE SALVO, Economia Privata e Pubblici servizi... p. 23 ss.
} 
configuración de las disposiciones contenidas en el CNRRN, sobre la remoción de los bienes procedentes de un naufragio, puesto que muchos de los principios y bases de la regulación actual encuentran su origen en las disposiciones del derecho romano, partiendo de la base de que en dicha época no podemos hablar del concepto de remoción, y que, como antecedente del mismo nos debemos remitir al llamado ius naufragiï y a las operaciones de salvamento y recuperación de mercancías llevadas a cabo por los urinatoresy los scaphari.

Así, vemos como el Convenio de Nairobi, impone la obligación de comunicar la existencia de un accidente marítimo que haya ocasionado restos de naufragio para la adopción de las medidas necesarias para asegurar el lugar, evitar el daño y la retirada de los mismos, como ocurría en Derecho Romano, en virtud de lo dispuesto en el C.1 1.6.1, con la salvedad de que con la relatio, y la posterior investigación, lo que se perseguía era la depuración de responsabilidades, y no la retirada de los bienes hundidos, como dijimos, por las limitaciones técnicas existentes en la época, tanto para evitar el riesgo, como para la recuperación, en el supuesto de que fuera inevitable. Por otro lado, se impone el deber del propietario inscrito de proceder a la remoción de los restos del naufragio, por si, o mediante la intermediación de un tercero en virtud de una relación contractual, que de ser considerada como operación de salvamento, excluye la aplicación del mencionado Convenio, en consonancia con lo dispuesto por Juliano en D.14.2.8, donde se obliga al titular de las mercancías arrojadas o hundidas, a realizar las labores de búsqueda y recuperación, y lo dispuesto por Calístrato en D.14.2.4.1, sobre la posibilidad de contratar los servicios de los urinatores a cambio del abono de una remuneración, que hemos considerado como operaciones de salvamento marítimo, puesto que concurren los elementos que imponen tanto el CISM como la LNM, para resultar de aplicación, como son, el resultado útil, entendido como la efectiva recuperación, la existencia de peligro y los riesgos tanto para la navegación como para el medio ambiente marino.

Finalmente, vemos como en materia de responsabilidad también existen coincidencias con las disposiciones del Derecho Romano, puesto que, salvo la concurrencia de fuerza mayor, acción de un terceros o conducta negligente de los Estados ribereños, es el propietario de la nave el responsable de asumir los costes de las operaciones tendentes a la evitación del riesgo o la minoración de los mismos. Ahora bien, en este contexto, el Derecho Romano, establece una clara diferencia entre la responsabilidad objetiva inherente al contrato de transporte, asumida por el navicularius, y la obligación del propietario de las mercancías de iniciar las labores de búsqueda o contratar los servicios de profesionales para tal fin.

En ese sentido, si bien, entendemos que los objetivos que se persiguen con las disposiciones del Convenio, de asegurar la navegación, de evitar riesgos, de preservar el medio ambiente marino, de garantizar los legítimos intereses de los Estados ribereños que pudieran resultar perjudicados por siniestro, no coinciden, obviamente, con los planteamientos de los legisladores romanos, que primaban el respeto a la propiedad de los bienes naufragados, y la tutela a sus legítimos propietarios, frente a cualquier otra circunstancia, como puede ser, la 
protección del medio o evitar la contaminación, podemos interpretar, que la labor que realizaban los urinatores en los puertos, removiendo y extrayendo periódicamente la acumulación de residuos, garantizaba el funcionamiento de la estructura pública y pone de manifiesto también, el interés de la annona por mantener limpios los puertos, evitando con ello, la producción de accidentes por la imposibilidad debido a la existencia de restos, de atracar en los mismos.

Por último, es evidente la base romanística existente tanto en la configuración de la normativa nacional en materia de salvamento, como en la normativa internacional por la que se rigen los Estados, como es el caso del citado Convenio de Nairobi, que como hemos podido analizar persigue la uniformidad normativa en el plano internacional.

\title{
ON THE REMOVAL OF SHIPWRECK: FROM ROMAN LAW TO THE 2007 NAIROBI CONVENTION
}

\begin{abstract}
In the present study, we intend to address some aspects related to salvage, focusing mainly on the removal and extraction of remains from an incident in navigation, trying to establish a point of connection between principles based on romanistics on the subject matter and the provisions of The Nairobi International Convention on the Removal of Wrecks, dated May 18, 2007, which entered into force on April 14, 2015 for the countries that signed it. For this, our methodology is based on the exegetical analysis of the proposed Roman sources. The results that are reflected in the concluding notes allow us to observe how there is a connection between the Roman Law and the norms contained in the Convention.
\end{abstract}

Keywords: Nairobi Convention, Naufragium, Damage, Removal, Responsibility.

Trabalho enviado em 12 de abril de 2018.

Aceito em 25 de março de 2018. 